\title{
One Form, Many Letters: Fluid and transient letterforms in screen-based typographic artefacts
}

\author{
BARBARA BROWNIE, University of Hertfordshire
}

\begin{abstract}
Current understanding of the nature of type assumes it to be static, with properties of form and colour. With the introduction of temporal media, typographic artefacts may additionally have properties of behaviour. Temporal media allow type to perform and evolve. 'Fluid' (Kac, 1997) type, as it appears in onscreen, is 'dramatized' (Helfand, 1997). A single form may present multiple letters through processes of morphing, rotation or deconstruction, and multiple forms may present a single letter through processes of reorganisation.

Analysis of such artefacts not only requires us to re-evaluate our understanding of the nature of type, but also to reassess the notion that a single letterform may only have a single identity. Referencing examples of typographic performance, this paper will discuss the nature of fluid type, and propose that current typographic theory may need to adapt in order to respond to the introduction of temporal media.
\end{abstract}

\section{KEYWORDS}

Temporal Typography, kinetic typography, fluid typography, film title sequences.

\section{Introduction: Temporal Typography}

Past understanding of the nature of typography, and the vocabulary used to define it, has assumed it to be static. In print, type is fixed, static and permanent, and on-screen, though not permanent, type is largely inanimate. Even with the introduction of hypertext, which allows navigation between documents, and for letterforms to become 'active' hyperlinks, text is still largely assumed to be an inactive tool of communication. However, as Jessica Helfand (1997, p.71), notes, with the dynamic capabilities of contemporary, digital media, 'our static definitions of type appear increasingly imperilled.'

It can be suggested that 'one of the decisive dividing lines between digital literature and print literature' is 'textual motion' (Ikonen, 2003). Printed type has seen 'analogy of motion' in works by Futurist typographers such as F.T. Marinetti and, later, 'Concretist poets' (Ibid.). Now, digital media offer the opportunity for typography that has a genuine temporal dimension, in which letterforms can move and change. As Michael Worthington (1998, p.9) observes, 'in a time-based medium, type has 
additional expressive qualities, additional layers of significance,' and additional dimensions that are impossible to recreate in print.

Multimedia offers typographers the opportunity to 'dramatize' (Helfand, 1997, p.49) type, for letterforms to become 'fluid' (Kac, 1996) and 'kinetic' (Engel at al, 2000). Film title credits present typographic information over time, often bringing it to life through animation. Motion graphics, particularly the brand identities of film and television production companies, increasingly contain animated type. Software such as Macromedia Flash has allowed for the creation of animated poetry and kinetic typography. Examples of 'type in motion' in temporal media have become a quotidian.

Academic research has begun to classify temporal typography and identify its potential uses. Theorists including Jessica Helfand (1997, p.51) have suggested that type may, with new technology, be given 'a theatrical component'. Helfand emphasizes the expressive potential of such typography, stressing that traditional, static characteristics, such as 'bold and italic', offer only a fraction of the expressive potential of dynamic properties. Soo C. Hostetler (2006) describes 'kinetic typography' in distinctly human terms, likening its motion to human gestures. George Borzyshowski (2004) acknowledges that new software allows designers to give text 'spatial temporal' dimensions (resulting in type in motion), and can offer 'morphological control'. He observes that animated typography allow text to 'fulfil a didactic function beyond nomenclature'.

As temporal typography is still an emerging field, it is perhaps unsurprising that theorists fail to agree on definitions of key terms, including 'kinetic typography', 'dynamic typography' and 'motion typography'. Furthermore, most neglect to differentiate between the different kinds of behaviour exhibited in temporal typography. In their three books on the subject, Woolman and Bellantoni (1999, 2000 and 2005) discuss 'type in motion', but, as Matthias Hillner observes, they fail to offer a 'concise explanation of 'type in motion' or 'moving type' (2005, p.166). Woolman and Bellantoni reduce all forms of temporal typography to a single, 'umbrella' definition, describing 'moving type' as 'typography that moves, transforms, mutates, duplicates, blurs [and] interacts' (Woolman and Bellantoni, 2000, p.7), resulting in generalizations that are not always applicable. Despite having observed flaws in Woolman and Bellantoni's work, Hillner's texts also make omissions. Hillner is responsible for numerous fonts that have been distinctly designed for temporal environments, constructed of or containing elements that move. His typographic animations have the potential to inspire discussion of perceived fluctuation and metamorphosis, and yet Hillner's own text, 'Text in [e]motion' fails to fully engage with the topic of transformation. He offers a definition of 'type in motion' that is startlingly strict. He suggests that 'kinetic type' could be defined as 'text that moves in relation to screen dimensions', or that involves 'change in position of [typographic] objects in relation to each other' (Hillner, 2005, p.166). Neither of these descriptions allow for the perceived fluctuation of form that is evident in Hillner's own animations.

When discussing his own work, in 'Virtual Typography: Time Perception in Relation to Digital Communication', Hillner focuses on the motion of 'individually moving text elements' (Hillner, 2006, p.1). He suggests that the terminology currently in use 
in descriptions of 'screen based' typography is outdated and inadequate, and offers the term 'virtual typography' for use in defining 'text elements' which 'change their position in relation to one another' or that may be navigated through 'virtually' (Ibid., p.2). Although this definition is relatively clear and concise, there is considerable overlap between it and other authors' definitions of 'kinetic typography'(see Hostetler, 2006, and Lee at al, 2002). Hillner also does not divide 'virtual typography' into further sub-categories, despite the startling differences between artefacts which could be grouped under this general heading. Furthermore, when Hillner refers to 'dynamic typography' later in his text, he labels it as 'responsive text' (i.e. text that only changes in response to user interaction), a definition that is in direct contradiction to other authors' implicit views that 'dynamic text' may move independently (see Specht, 2000, Ikonen, 2003, and Helfand, 1997).

Hillner begins to approach an identification of a distinct category of kinetic typography when he describes how, in his own work, 'letterforms may emerge from and merge into illegible visual elements' (2006, p.3). This is a behaviour that is not currently universal to any defined category of kinetic or dynamic typography, and could therefore potentially offer the opportunity to differentiate between this and other kinds of moving text. Unfortunately, Hillner still refers to these artefacts as 'virtual typography' (Ibid. p.3), thereby implying that there is no distinct difference between text that appears to 'merge' and text that simply moves.

Although Hillner himself does not label or categorise the perceived transformation of forms within his animations, other theorists have begun to suggest that such events may be significant. Lee, Forlizzi and Hudson acknowledge that 'malleable' letterforms may be dramatically 'manipulated', but only insofar as they 'appear to be completely different type faces' (2002, p.84). This does not allow for more extreme manipulation, which would result in a form becoming unrecognisable as a letter. Woolman and Bellatoni also acknowledge that text may 'transform' or 'distort', through 'blurring, fracturing and cropping' (2000, p.36), and that onscreen type may present 'transitions between the characteristics of a letter' (Ibid., p.34). However, their descriptions imply that these changes are slight, altering legibility and mood but not resulting in total change. What these theorists fail to identify is a category of typography in which letters change or transform completely, to the extent that they appear to adopt new identities. There is an assumption, even among practitioners, that the key, defining feature of kinetic or dynamic typography is motion, not other kinds of change. With this assumption, there are numerous artefacts that are inadequately described.

Nikita Pashenkov, creator of Alphabot (2001), a virtual robot that may transform to take the shape of any letter of the alphabet, has produced interactive artefacts that could fall into the same undefined category as Hillner's transformative fonts. In animations of the Alphabot, letterforms are 'malleable', capable of altering their form (Pashenkov, 2001). This transformation is distinctly different to change in location (or, 'motion') and is more than a change in style, as suggested by Woomlan and Bellatoni. It is a total change in the identity of the presented form. The 'robot' transforms, becoming the letter 'A', then the letter ' $\mathrm{B}$ ', and so on. Without moving, it changes; it assumes a new identity. 
Likewise, numerous other artists have produced typographic artefacts that appear to fall into this undefined category; works which are more than just kinetic. These works do not just present change on a global scale (that is, change in overall layout or 'type in motion'), but change at a local level; change within individual letterforms.

In Beer, a Flash animation by Komninos Zervos (2005), letterforms transform, morphing from one shape into another, each form presenting multiple letters as it evolves over time. In Harm Van Der Dorpel's animations, Type Engine and I Wouldn't Normally do this Kind of Thing (both 2005), abstract elements are rearranged to form a phrase, then disassemble and reassemble to form another. In both these artists' examples, the letters are not so much in motion as in flux. They change within space rather than move across space.

Teemu Ikonen offers a definition of motion that, more so than any of the theorists quoted so far, allows for kinetic typography to both move and change. He suggests that motion can refer to "change of pace, rotation, pendulum motion...jointed motion, elastic motion, 'flow', and, critically 'change of form'(Ikonen, 2003). Once this new definition of motion is acknowledged, the term 'type-in-motion' becomes suitable for use in describing not only type that changes location, but also type that alters in form. Ikonen identifies 'non-rigid objects' and 'a 'dynamic grammar' in which...signs change their form'(Ibid.), and acknowledges the work of Eduardo Kac as being particularly relevant to the potential for signs to change over time.

Eduardo Kac produced 'holopoems' from 1983 onwards. These visual poems, displayed as holograms, appeared to 'change their configuration in time' (Kac, 1997) in that, as the viewer moves around each piece, it not only appears to be in motion, but also to 'exhibit... behaviour'(Ibid.). From different locations, viewers would observe different formations of letters. When moving around a 'holopoem', the viewer's experience takes on a temporal dimension, as it appeared that each letterform would change over time. Kac described his works as containing 'fluid signs', or signs that alter over time, "therefore escaping the constancy of meaning a printed sign would have'(Ibid.). They are capable of 'metamorphoses between a word and an abstract shape, or between a word and a scene or object'(Ibid.). Kac's definition of 'fluid' typography, though not intended for onscreen artefacts, would be aptly used to describe the digital artefacts by Komninos Zervos and Harm Van Der Dorpel. Just as in Kac's holopoems, contemporary onscreen typography can alter its form and meaning.

To date, the most extensive investigation into temporal typography, and the one most likely to offer a vocabulary for the analysis of digital, 'fluid' typography, has been Y. Y. Wong's Temporal Typography: Characterization of time-varying typographic forms (1995). The thesis presents a model of analysis for temporal typography (screen-based typography with a temporal dimension). Wong acknowledges that typographic theory, despite having developed thorough methods of analysis and description for static type, has yet to develop models for the 'characterization'(Ibid., p.7) of temporal typography. Wong makes more progress than other theorists towards a definition of onscreen, fluid type, in that she identifies 'deformation' of type (Ibid., p.21). This term is used to describe type which loses its identity through distortion, but unlike Kac, Wong neglects to acknowledge in her definition that deformation could lead to the formation of other identities. 
Wong, like other theorists, fails to make substantial progress towards identifying and analysing digital, screen-based typography that alters its identity over time. Although terms are offered by Wong and other theorists, none seem as apt in defining these artefacts as Kac's term, 'fluid'. Ikonen (2003) acknowledges this distinct similarity between Kac's holopoems and the events seen in some kinetic typography. He observes that 'transitional stages between recognisable letters' occur in both Kac's work and more recent digital artefacts, and begs that 'the challenge...be taken to develop means of analysing and describing' this transition.

\section{'Fluid' Type and its place alongside other temporal typography}

As made evident above, there is a startling lack of clarity or consensus among theorists as to what constitutes 'dynamic', 'temporal' and 'kinetic' typography. The terms are often used interchangeably, and definitions often come into conflict. A generally held understanding is that 'temporal' typography, by any name, involves motion, but distinctions are rarely made between different kinds of motion, or motion and other kinds of change. Even the definition of 'type in motion' appears to vary between texts. However, through analyses of the texts cited above, and the examples to which their authors refer, one can begin to form a model of the different kinds of behaviour that are presented within screen-based typographic artefacts.

The screen-based typography discussed by the aforementioned theorists, whether on computer, television or cinema screen, has a temporal dimension. It changes over time, presenting multiple images or arrangements. This temporality is the single feature that is common to all of the examples selected for description and analysis in the texts discussed above. 'Temporal typography' shall therefore be used in this document as a general, universal term to describe all kinds of artefact in which type is presented over time on a screen.

Temporal typography can be divided into two distinctly separate categories. The first of these involves words that are 'presented serially through time' (Wong, 1995, p.30). In serial presentation, words are static. They neither move nor change, and are, in all respects, arranged and displayed in the same way as words on a printed page. Still arrangements of words are presented in sequence, as in early title cards. For these, 'type was printed on a card which was filmed directly' (Woolman and Bellantoni, 2000, p.15). Static text is still seen in title credits, as well as in advertising and other temporal media, though this method has since been improved and updated, now involving digital production of the text. Serial presentation of static typographic compositions has also been used in research into reading processes and legibility. One method of presentation used in cognitive psychology research has been referred to as 'RSVP' ('Rapid Serial Visual Presentation') in which text is presented 'in the same location serially' (Wong, 1995, p.49). This category of temporal typography, that is a sequence of static typographic layouts, will be referred to as 'serial presentation'.

Serial presentations may feature a number of transitions which may create the impression that the text is in some way dynamic. Cinematic transitions including fades (between two different still frames) or wipes (which reveal the next frame as if it were hidden behind the last) can be used as an alternative to a simple cut from one 
still typographic composition to the next (Woolman and Bellantoni, 2000. p.58). Although these transitions may themselves be kinetic, the text compositions to which they are applied remains static.

The Cautionary Tale, by Claire Mason (2006), demonstrates serial presentation in an animated form. In this animation, a dialogue is presented in static words which are introduced one by one, building to complete phrases and sentences. The rhythm of the presentation of words imitates spoken dialogue. Each typographic scene alters over time, which may suggest motion, but the words that appear are static, and are introduced sequentially.
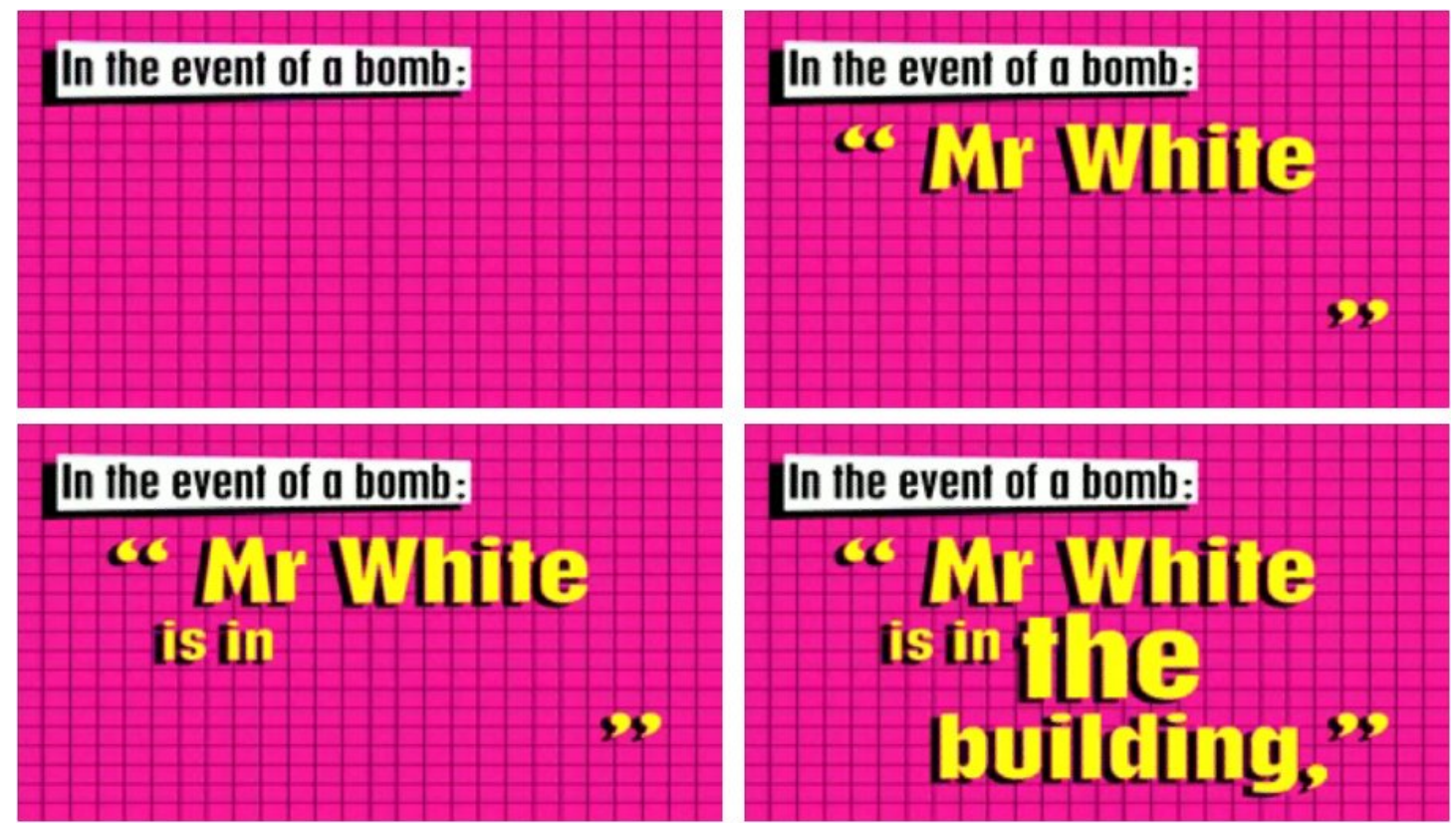

Stills captured from Mason, C., 2006, The Cautionary Tale, animated motion typography, UK.

The second category of temporal typography includes all onscreen type that is not static; type that moves or changes in any way. This category is largely referred to by theorists and practitioners as 'kinetic type'. Some texts describe 'dynamic type' in similar, if not identical terms. As a result, it can be observed that these terms are often interchangeable. For the purposes of this research, I shall be using the term 'kinetic typography' in order to describe all typography that is rearranged (i.e. that is 'in motion') or transformed on the screen, regardless of the cause of the change that occurs (be it spontaneous or as a result of user interaction).

Within this category of kinetic typography, artefacts differ widely. The theorists discussed above have yet to agree on terms or descriptions to distinguish between the different kinds of behaviour exhibited in kinetic typographic artefacts, but many useful suggestions are offered. Kinetic typography can be further separated into two categories which distinguish change that occurs on global scale from change that occurs at a local level. Global change involves change in overall layout; the arrangement of letters on the screen varies progressively. Local change involves change within individual letterforms, resulting in a transformation of the form.

The majority of kinetic typography falls into the category of 'type in motion', which includes all type which changes location (i.e. all global change) without other 
transformations. Motion can alter layout in different ways, and this category therefore requires further sub-categories. The most basic kind of 'type in motion' is text which simply scrolls. In 'scrolling typography', elements remain at a constant distance from one another, moving as a unified whole. The entire composition moves across, up or down the screen. The origin and destination of the text appear to be at imagined locations off-screen, with the frame perceived as a 'window' (Woolman and Ballantoni, 2000, p.23) through which the text can be observed, not a 'room' (Ibid.) that contains it. The way in which text scrolls simulates the act of reading, tending to scroll upwards or from left to right, in a mirror image of the reading process. As with serially presented text, research into the legibility of scrolling text has been carried out, specifically in regard to text presented using the 'Times Square method', in which text is moved 'from right to left in a continuous manner'(Wong, 1995, p.48). In everyday environments, scrolling text is most commonly encountered in closing credits in film or television.

A more complex form of 'type in motion' involves text elements which change their location both in relation to the frame and 'in relation to each other' (Hillner, 2005, p.166). Such change can be observed in David do van Minh's Les Voyages en Train Grand Corps Malade (2006). In this animation, words and phrases move independently of one another. Some phrases scroll while others rotate, resulting in constant change in the arrangement of the words on the screen. This kind of artefact can be described as having a 'dynamic layout'.
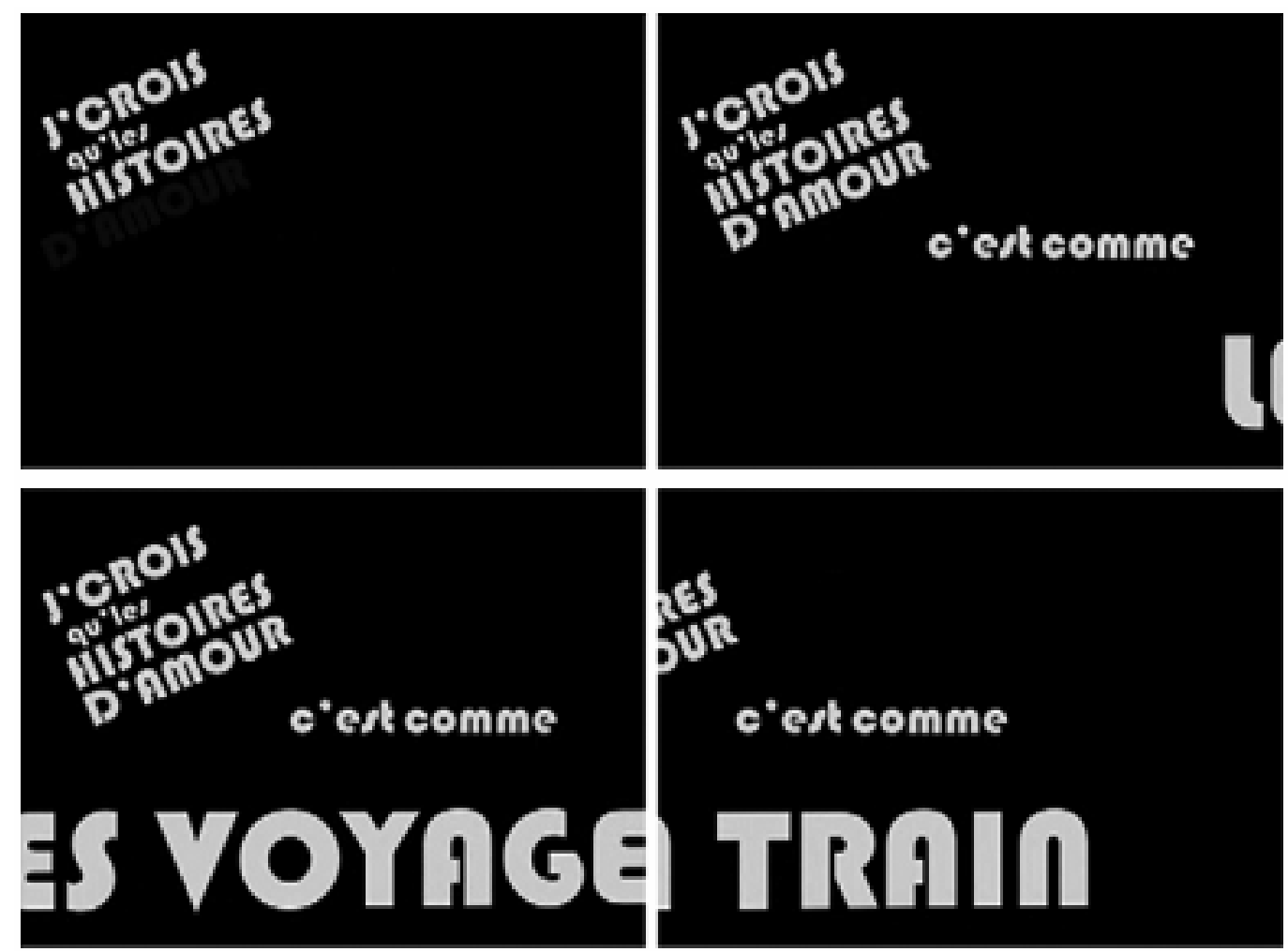

Stills captured from Do van Minh, D., 2006, Les Voyages en Train Grand Corps Malade, typographic animation, France.

Other kinetic typography, involves change at a local level. This can be described by transposing Kac's term 'fluid' (1997) from its original use in the description of 
holographic poetry, to a new application in the study of screen-based, temporal typography. 'Fluid typography' presents letterforms that are transient and changeable. Their form, their silhouette, alters over time, without there necessarily occurring a change in the location of the form (though these categories are not mutually exclusive; moving objects can also be fluid). This is the kind of kinetic typography that is currently most lacking in explorative and explanatory research.

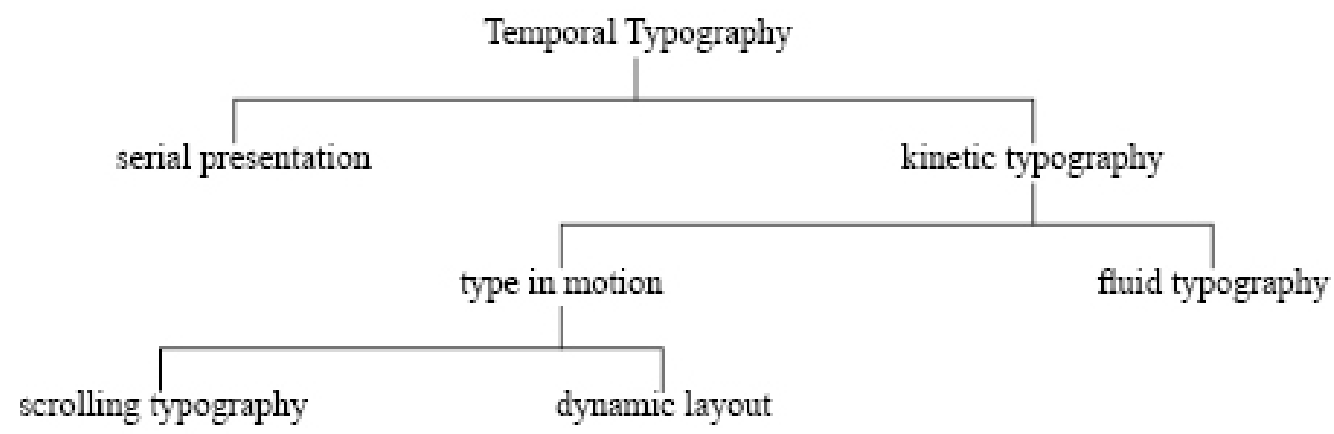

A fluid form does not have fixed contours. It may be interrupted, mutated, fractured or changed in numerous other ways. Wong, Woolman and Bellantoni have identified how letters can be stretched, distorted and 'deformed' (Wong, 1995, p.21) but fluidity is more than simply a subtle adjustment to the silhouette of a form. In order to be defined as 'fluid', a form must exhibit change so extensive that results in new identities and new meanings.

As Kac observed in relation to his holographic poetry, a 'fluid' sign 'escap[es] the consistency of meaning a printed sign would have.'(Kac, 1997). The same description can be applied to digital, onscreen, fluid typography. Fluid signs can present multiple meanings. A Fluid form evolves over time to the extent that its meaning also changes. A fluid sign is 'not either one thing or another'(Ibid.); its form is constantly in flux, as is its identity. A single form may be observed in once instance as having a letter identity, and at another instance, once it has transformed, as presenting another identity. An additional identity is introduced without the introduction of an additional form. This results in a separation of letter and form, causing the idea and label of 'letterform' to become insufficient, or even obsolete.

Woolman and Bellatoni acknowledge that new media and digital technologies are 'placing the simple letterforms - the symbols of language and communication - in formal and functional jeopardy'(2000, p.7). In fluid typography, forms do not function purely as letters. The meaning of the word 'letterform' is only partially or momentarily applicable, as fluid forms are only fleetingly letters, and otherwise something else. A form may present a letter identity, and be perceived as a letterform, but that form changes, becoming an abstract glyph, an object or a shape. There is, therefore, a separation of letter and form.

Not all changes which occur within a letterform cause it to become fluid. Among examples of kinetic typography, letters that alter their style and perceived meaning are 
relatively common; even a simple transition such as a fade may alter the silhouette of a letterform, and our impression of the stability of that form. Wong observes that the 'meaning' of a word or phrase in temporal typography can be altered or even 'reversed' through changes in the rhythm of a presentation. She suggests, for example, that 'a slowed presentation speed may express uncertainty' (Wong, 1995, p.41). It is important to note that this kind of change does not equate to fluidity. The change in meaning that Wong describes is not a result in a change in identity, but of new connotations that are perceived when the form changes slightly, or its 'manner of movement'(Ibid.) is altered. New characteristics may be added or removed to the extent that a letterform appears to take on a new persona, however its underlying identity may remain fixed.

\section{Fluid Type: One Form/Many Letters, Many Letters/One Form}

Through observations of examples of fluid typography in title credits, interactive artefacts, digital animation and motion graphics, one striking characteristic of fluid type has become evident: Because a fluid letterform can evolve, it can assume multiple different identities. It can present one letter, then evolve to another. It may even evolve to adopt an identity that is not a letter at all - perhaps a shape or object. It 'can operate metamorphoses between a word and an abstract shape, or between a word and a scene or object' (Kac, 1996)

In static or scrolling typography (in print or on-screen), a single letterform presents a single identity. Each letterform is both a single letter, and a single form. It has a single identity. When an additional letter is introduced, it is introduced as an additional form. The number of forms present, therefore, matches the number of letters (and the number of identities). In static or simple moving typography, each form retains a distinct, permanent identity.

A fluid letterform, however, does not have a fixed form. It may evolve, change, and, crucially, it may assume new identities. This allows for the introduction of a new identity without the introduction of an additional form, and is a defining characteristic of fluid type.

In Beer, an animation by Komninos Zervos (2005), letters morph into one another. Each form initially presents itself as a letter, then morphs, producing intermediate, abstract glyphs before it adopts the form of another letter. Each new identity is adopted through a languid, fluid metamorphosis, which reflects the properties of a drunken slur.

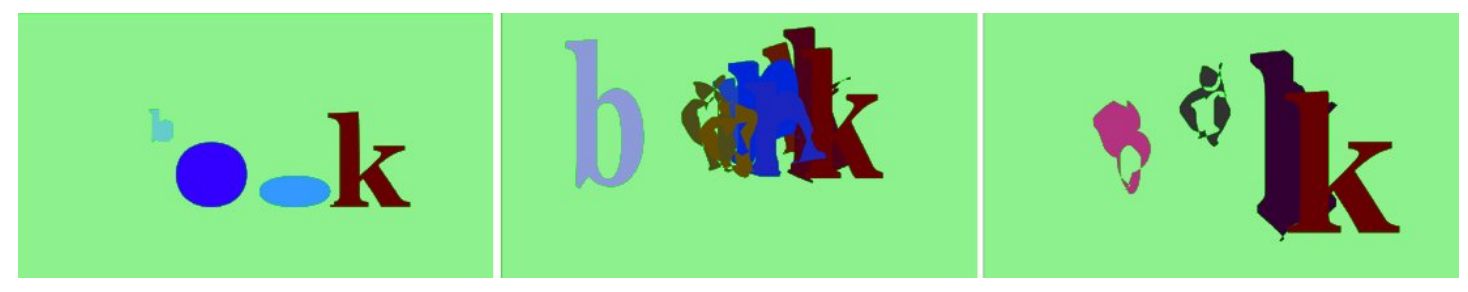

Stills captured from Zervos, K., 2005, Beer, Flash animation, Australia. 
From other examples of fluid type, we can see that this inconsistency between the number of perceived identities and the number of actual forms is not restricted to metamorphosis between letters. There are numerous ways in which this inconsistency is presented, through processes of rotation, navigation, deconstruction and reconstruction. In some instances, multiple forms can come together to present a single identity, in others, multiple identities are perceived within a single form.

In Letterscapes (W) by Peter Cho (2001) viewers initially perceive a number of different, triangular shapes. Each of these triangles is interpreted as having an independent identity. However, as these shapes rearrange, they merge to form a new identity, the letter ' $W$ '. Despite having been initially perceived different forms, when combined they are perceived only as parts of a greater whole.

MPC (The Moving Picture Company) have produced a number of idents for channel 4 containing examples of fluid typography. In Tokyo (MPC, 2005), the viewer is presented with several architectural street signs. Initially, each sign is perceived as being a separate object, and as an integral part of the Tokyo cityscape. These distinctly separate objects align and adopt a new, group identity, that of a '4'. After being presented with this new arrangement, viewers no longer perceive the signs as integrated into the cityscape, but into the figure ' 4 '. The primary purpose and meaning of each sign shifts from that of an independent object to that of a component part of a more significant arrangement.

\section{Multiple Meanings}

In examples of fluid typography, fluidity can lead not only to new identities being introduced, but also new meanings. Newly introduced identities can reinforce the initial perception of a form, clarify it, or, in some cases, contradict it.

In Kyle Cooper's title sequence for True Lies (1994), the initial identity presented to the viewer is that of the word 'true'. When this word rotates, the viewer is made aware that the word is not formed of flat letters but the surfaces of three-dimensional shapes. Cut into the side of each of these forms is a void. These voids present the word 'lies'. This second identity contradicts the initial meaning of the forms in two ways. Firstly the word 'lies' contradicts the word 'true', suggesting that we should reevaluate our perception of the initial identity. Secondly, it presents this new identity as voids rather than as objects; as negative rather than positive spaces. This reaffirms our understanding that truth and lies are distinctly different, with contradictory properties.

As the forms in this title sequence begin to revolve, the viewer's perception of the nature of the forms, and indeed the nature of the space they occupy, also changes. Initially, as the viewer is only presented with the face of the letters in 'true', they perceive them as flat forms on a single plane. However, once the forms have begun to revolve, they reveal themselves as having volume. This requires the viewer to reassess his or her perception of the form. At the same time, the viewer must acknowledge that the space which these forms inhabit must also have depth. The background itself is black, and contains no indication of whether it is intended as two-dimensional or three-dimensional As a result, the viewer must take cues from the objects within it in order to assess its nature. As soon as the perceived nature of the forms changes, so too 
must the perception of the space they occupy. So, the viewer's initial perception of two-dimensional forms must change to that of three-dimensional objects, while his or her perception of the space the forms occupy changes simultaneously. It is no longer perceived as a flat plane, but as 'environmental space'(Palmer et al, 1988), that is, space with virtual depth.

When viewing examples of fluid typography, observers find that forms fluctuate between more abstract identities and more meaningful signs. There is a moment at the 'poles' (Kac, 1997) in which they present a perfect letter or sign, but between the poles abstract shapes are presented as one letter disassembles, and the next is formed.

Matthias Hillner, who has created fonts intended for use in fluid artefacts, suggests that a fluid form is not only legible in the instant in which it presents a perfect letter, but also when it is an approximation of that letter - as it approaches the poles. In Zervos' Beer, for example, as each form morphs between abstract glyph and letter it presents, for a short while, forms resembling misshapen, drunken letters, which are legible but imperfect. These 'fluctuating levels of legibility' (Hillner, c.2004) cause the viewer to anticipate forthcoming letters.

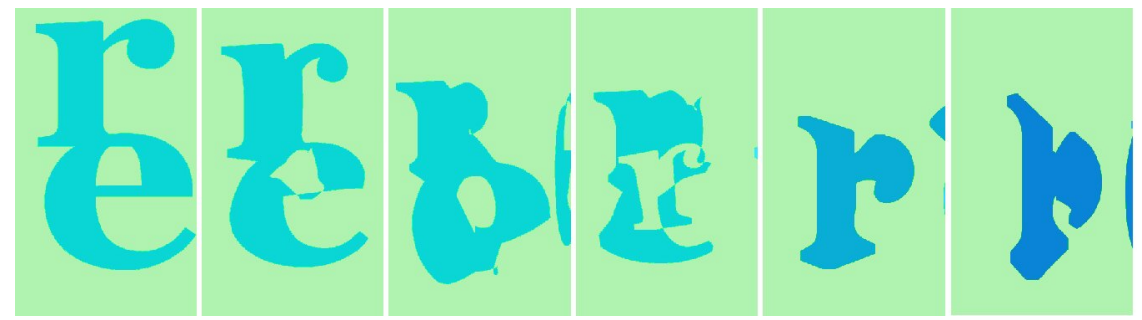

In Komninos Zervos' Beer (Zervos, 2005), the letters ' $r$ ' and 'e' morph and merge, creating intermediate glyphs before they begin to re-form into the letter ' $h$ '.

When handwriting, a writer will adjust the way a letter is formed in anticipation of the next (Orliaguet et al, 1997). Depending on what letter he expects to write next, the letter he is currently forming will vary in 'thickness', 'curvature' and 'slant' (Ibid. p.911). It is therefore possible to predict what letter a writer is about to create by observing the formation of previous letters. In fluid typography, the viewer can begin to predict what letter will appear next, and how it will appear, through various cues that are specific to the individual artefact. In general, as a form or arrangement begins to approach a letter, its next identity will become easier to predict.

In Dan Waber's Poidog (2005), a single string stretches and reforms to present a series of words. As the 'string' begins to reform, the angles and curves that begin to appear give viewers an indication of the next form it is likely to assume.

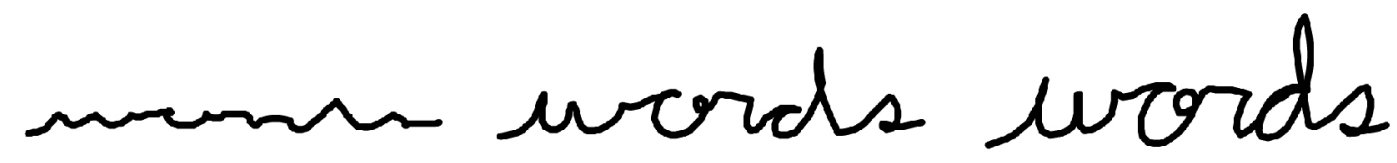

Waber, D., 2005, Poidog, Flash animation, USA. The text begins to become legible before it is fully formed, causing the viewer to anticipate the next word. 
Similar indicators are present when a fluid letter is constructed out of separate parts, as in MPC's Tokyo, and in the following example, Orgdot's The ABC Game (2003). In The ABC Game, players must construct a letter from abstract, linear parts. The nature of the parts, particularly their curvature, can act as an indication of the role they will play when rearranged to form a letter.

When viewing examples such as MPC's Tokyo ident, it is likely to be the case that viewers will anticipate the ' 4 ' both because of the visual cues given by the existing forms, and because they have come to expect it. Similarly, in many other artefacts, if viewers are made aware that an apparently abstract form will eventually present a letter they are likely to seek-out that letter by attempting to analyse various cues within the existing abstract forms.

However, it is important to note that the aim of fluid typography is not entirely to present letters. It is the nature of fluid typography that other shapes and signs are also presented within the same forms or arrangements as the letter(s). In Beer, for example, the forms fluctuate between legible letter and more abstract glyph. These 'in-between' forms are 'as important... as the meanings produced momentarily at the poles.' Fluid typography introduces this 'new kind of verbal unit, in which a sign is not either one thing or another' (Kac, 1997).

\section{Conclusion}

The theorists referenced so far all agree that 'dynamic, or moving typography raises issues that are different from those found in typography existing in printed form' (Specht, 2000, p.1), and as a consequence, that current typographic theory is often inadequate to define and analyse kinetic and fluid type. Heidi Specht suggests that, 'dynamic typography, by its very nature, negates many principles that can be applied to static typography' (Ibid., p.10). Common to all of the above texts is an assumption that kinetic typography largely concerns 'type in motion', that is, type which changes location over time, causing rearrangement of on-screen layout. They largely fail to differentiate between this kind of global change in layout, and change at a more local scale, within individual letterforms. Ford, Forlizzi and Ishazaki, for example, define kinetic typography as able to 'change colour, size, or position over time'(Ford et al, 1997) neglecting to acknowledge change in meaning, form or identity. Lee, Forlizzi and Hudson, define 'kinetic typography' vaguely as 'text that uses movement or other temporal change' (Lee et al, 2002, p.81), discussing both global change (in layout) and local change (within letterforms) in the same terms, and in doing so, failing to acknowledge that the two are distinctly different. Soo C. Hostetler (2006) defines 'kinetic typography' simply as 'the combination of typography and motion', and goes on to identify its common attributes. During this discussion she describes how a letterform may become 'abstract', no longer identifiable as a letter, because it has been 'manipulated by distortion, texture [or] enlargement' (Ibid.). However, she fails to discuss this issue further, and misses the opportunity to speculate as to the possible consequences of this change, or identify it as significantly different to type which simply moves.

Typography which exhibits change at a local level, and presents multiple identities over time, is rapidly becoming commonplace. There are numerous examples of these 
artefacts containing type which could be described using Kac's definition of 'fluid'. Academic writings largely fail to identify or analyse this kind of behaviour, despite extensive discussion of temporal and kinetic typography. There is, at present, no substantial research into the properties and perception of fluid typographic artefacts. Current possible methods of analysis, which rely heavily on the pre-existing and limited terminology of film and static type, are inadequate to define and analyse fluid type. Familiar methods for the analysis of typography have failed to keep pace with the development of digital technologies. They do not allow for the additional dimensions that are seen in fluid type; type which is capable of performance and reactivity, and vitally, as I have described, type which separates letter from form (type which allows a single form to present multiple letters, and vice versa). Therefore, our understanding of the nature of type, and how it may be analysed, must be modified and updated. My research will focus on advancing the understanding of the nature and perception of fluid typography, and aim to provide new and updated models with which future analysis will be possible.

\section{References}

Borzykowski, G. (2004) Animated Text: More than meets the eye? In McBeath, C., Jonas-Dwyer, D. and Philips, R., eds. Beyond the Comfort Zoe: Proceedings of the $21^{\text {st }}$ ASCILITE Conference, Perth, 5-8 December 2004 Perth. Available from: http://www.ascilite.org.au/conferences/perth04/procs/borzykowski.html [Accessed 14 December 2006] pp.141-144

Cho, P. (2001) Letterscapes, interactive animation, USA [online]. Available from: http://www.typotopo.com/letterscapes/letterscapes.html [Accessed 18 April 2007]

Cooper, K. (1994) True Lies, title sequence, USA, in True Lies, 1994, film, directed by James Cameron, USA: Lightstorm Entertainment.

Do van Minh, D. (2006) Les Voyages en Train Grand Corps Malade, typographic animation, France [online]. Available from:

http://www.youtube.com/watch?v=FzR4J2kHenU [Accessed 21 May 2007]

Engel, B., Ditterline, P., and Yeung, B., (2000) The Effects of Kinetic Typography on Readability, Carnegie Mellon University [online]. Available from:

http://crankyuser.com/kinetic/kineticTypography.pdf [Accessed 12 April 2006]

Ford, S., Forlizzi, J. and Ishizaki, S. (1997) Kinetic Typography: Issues in time-based presentation of text. In Pemberton, S., ed. CHI 97Late Breaking/Short Demonstrations, Atlanta 25-27 March 1997. Available from: http://doi.acm.org/10.1145/1120212.1120387 [Accessed 19 June 2007]

Helfand, J. (1997) Electronic Typography: The New Visual Language. In Beirut, M. et al eds. Looking Closer 2: Critical Writings on Graphic Design: Canada: Allworth Press, 1997, pp. 49-53.

Hillner, M. (c.2004) Research: Proposition, Virtual Typography. [online]. Available from: http://www.virtualtypography.com/navigation/menu.html [Accessed 17 April 2007] 
Hillner, M. (2005) Text in (e)motion. Visual Communication. 4:165-177 [online]. Available from: http://vcj.sagepub.com [Accessed 14 February 2007]

Hillner, M. (2006) 'Virtual Typography': Time Perception in Relation to Digital Communication, LeonardoElectronic Almanac, 14; 05-06, [online]. Available from: http://leoalmanac.org/journal/vol_14/lea_v14_n05-06/mhillner_lea140506.pdf [Accessed 24 March 2007]

Hostetler, S. C. (2006) Integrating Typography and Motion in Visual Communication [online]. Available from:

http://www.units.muohio.edu/codeconference/papers/papers/Soo\%20Hostetler2006\%20iDMAa\%20Full\%20Paper.pdf [Accessed 04 January 2007]

Ikonen, T. (2003) Moving Text in Avant-Garde Poetry: Towards a Poetics of Textual Motion, Dichdung-digitalde Newsletter 4, [online]. Available from:

http://www.dichdung-digitalcom/2003/4-ikonen.htm. [Accessed 25 April 2006]

Kac, E., (1996) Key Concepts of Holopoetry. In Jacksin, D., Vos, E. and Drucker, J., eds. Experimental-Visual-Concrete: Avan-Garde Poetry Since the 1960s, GA,

Rodopi, 1996, pp.247-257. [online]. Available from:

http://www.electronicbookreview.com/thread/electropoetics/uncontrollable [Accessed 10 April 2006]

Lee, J. C., Forlizzi, J., and Hudson, S. E. (2002) The Kinetic Typography Engine: An Extensible System for Animating Expressive Text. In. Beaudouin-Lafon, M. $15^{\text {th }}$ annual ACM Symposium on User Interface Software and Technology, Paris, 27-30 October 2002. Paris: ACM Press. Available from:

http://www.cs.cmu.edu/ johnny/kt/dist/files/Kinetic_Typography.pdf [Accessed 24 March 2007]

Mason, C. (2006) The Cautionary Tale, animated motion typography, UK. [online]. Available from: http://www.youtube.com/watch?v=NjmKkiMGdnk [Accessed 01 August 2007]

MPC (The Moving Picture Company) (2005) Tokyo, Ident for Channel 4, UK [online]. Available from: http://www.moving-picture.com/4idents [Accessed 01 January 2007]

Orgdot (2003) The ABC Game, interactive animation, Norway [online]. Available from: http://www.orgdot.com/ABC/ [Accessed 01 January 2007]

Orliaguet, J., Kandel, S. and Boe, L. (1997) Visual perception of motor anticipation in cursive handwriting: Influence of special and movement information on the prediction of forthcoming letters. Perception, 26: 905-912.

Pashenkov, N. (2001) Alphabot, interactive animation, Japan.

Pashenkov, N. (2001) 'Alphabot' Interactive Design Work, TDC Annual Awards, Interactive Design Prize: Nikita Pashenkov, Tokyo TDC [online]. Available from: 
http://www.tdctokyo.org/awards/award01/01interactive_e.html [Accessed 18 April 2007]

Palmer, S., Simone, E. and Kube, P. (1988) Reference frame effects on shape perception in two versus three dimensions. Perception, 17: 147-163.

Rosenberger, T., and MacNiel, R. L. (1999) Prosodic Font: Translating Speech into Graphics, Proceedings of CHI'99 Extended Abstracts, Pittsburgh, 15-20 May 1999 [online]. Available from: http://alumni.media.mit.edu/ tara/CHI1999.pdf [Accessed 24 January 2007] pp.252-253

Specht, H. (2000) Legibility: How Precedents Established in Print Impact On-Screen and Dynamic Typography [online]. Available from:

https://eidr.wvu.edu/files/1426/Specht_H_Thesis.pdf [Accessed 24 January 2007]

Van der Dorpel, H. (2005) Type Engine, Flash animation, Netherlands [online]. Available from: http://www.harmlog.nl/harm/harmlog/main.asp?id=69 [Accessed 15 January 2007]

Van der Dorpel, H. (2005) I Wouldn't Normally do this Kind of Thing, Flash animation, Netherlands [online]. Available from:

http://www.harmlog.nl/harm/harmlog/main.asp?id=77\&action=prev\&sort=1 [Accessed 15 January 2007]

Waber, D. (2005) Poidog, from the Strings collection, Flash animation, USA [online]. Available from: http://www.vispo.com/guests/DanWaber/poidog.htm [Accessed 01 January 2007]

Wong, Y. Y. (1995) Temporal typography: characterization of time-varying typographic form. MS Thesis, MIT.

Woolman, M., and Bellatoni, J. (1999) Type in Motion: Innovations in Digital Graphics, China ,Thames \& Hudson.

Woolman, M. and Bellantoni, J. (2000) Moving Type, Singapore, Rotovision.

Woolman, M. (2005) Type in Motion 2, London,Thames \& Hudson.

Worthington, M. (1998) The New Seduction: Movable Type. AIGA Journal of Graphic Design, 16; 3, pp.9-10.

Zervos, K. (2005) Beer, Flash animation, Australia [online]. Available from http://www.allenandunwin.com/writingexp/beer.swf [Accessed 01 January 2007] 